\title{
Mid-Term Effects of Pulmonary Rehabilitation on Cognitive Function in People with Severe Chronic Obstructive Pulmonary Disease
}

This article was published in the following Dove Press journal: International Journal of Chronic Obstructive Pulmonary Disease

\author{
Tristan Bonnevie ${ }^{1,2}$ \\ Clement Medrinal (iD ${ }^{2,3}$ \\ Yann Combret ${ }^{4,5}$ \\ David Debeaumont ${ }^{6}$ \\ Bouchra Lamia ${ }^{2,3,7}$ \\ Jean-François Muir ${ }^{1,2,7}$ \\ Antoine Cuvelier $\mathbb{( D}^{2,7}$ \\ Guillaume Prieur ${ }^{2,3,5}$ \\ Francis-Edouard Gravier ${ }^{1,2}$ \\ 'ADIR Association, Rouen University \\ Hospital, Rouen, France; ${ }^{2}$ Normandy \\ University UNIROUEN, UPRES EA 3830, \\ Haute Normandie Research and \\ Biomedical Innovation, Rouen, France; \\ ${ }^{3}$ Intensive Care Unit Department, Le \\ Havre Hospital, Le Havre, France; \\ ${ }^{4}$ Physiotherapy Department, Le Havre \\ Hospital, Le Havre, France; ${ }^{5}$ Institute of \\ Experimental and Clinical Research \\ (IREC), Pole of Pulmonology, ORL and \\ Dermatology, Catholic University of \\ Louvain, Brussels, Belgium; ${ }^{6}$ Department \\ of Respiratory and Exercise Physiology \\ and CIC-CRB I404, Rouen University \\ Hospital, Rouen, France; ${ }^{7}$ Pulmonary, \\ Thoracic Oncology and Respiratory \\ Intensive Care Department, Rouen \\ University Hospital, Rouen, France
}

Correspondence: Tristan Bonnevie ADIR Association, Rouen University Hospital, Rouen, France

Tel +33 235592970

Fax +33 23559297I

Email rehabilitation@adir-

hautenormandie.com
Purpose: Cognitive dysfunction is a common impairment associated with COPD. However, little is known about 1) its prevalence among those subjects referred for pulmonary rehabilitation (PR), 2) how it may affect the benefit of PR, 3) whether PR improves cognitive function and 4) whether cognitive dysfunction affects the usability of telehealth technology usually used to deliver in-home PR.

Patients and Methods: Fifty-six subjects with stable COPD (54\% females, mean age 62 years (SD 9) and median $\mathrm{FEV}_{1} 0.9 \mathrm{~L}$ (IQR 0.7 to 1.1)) participated in this multicenter observational study and performed 24 sessions of PR. The Montreal Cognitive Assessment tool (MoCA) was used to assess the occurrence of mild cognitive dysfunction (using a screening cutoff $<26$ ) at baseline, completion of PR and 3 months of follow-up.

Results: Mild cognitive dysfunction was found in 41 subjects (73\% [95\% CI: 60 to 83\%]). The MoCA score significantly improved following PR for those people with baseline mild cognitive dysfunction $(\mathrm{p}<0.01)$. There was no significant difference in clinical outcomes between those people with or without mild cognitive dysfunction following PR nor in the proportion of subjects who were autonomous in using the telemonitoring system $(83 \%$ compared with $71 \%, \mathrm{p}=0.60)$.

Conclusion: Mild cognitive dysfunction is highly prevalent among those people with COPD referred for PR but does not affect the benefits of PR nor the usability of a telemonitoring system. PR may improve short- and mid-term cognitive function for those people who experience mild cognitive dysfunction at the time they are referred to PR.

Keywords: COPD, pulmonary rehabilitation, exercise, cognitive dysfunction

\section{Introduction}

Chronic obstructive pulmonary disease (COPD) is a leading cause of death worldwide ${ }^{1}$ and its prevalence, as high as $10 \%$ in adults over 40 years old, ${ }^{2}$ is planned to increase in the next decade. ${ }^{3}$ This respiratory disease progressively leads to physical inactivity, muscle deconditioning and worsening dyspnea. ${ }^{4}$ Pulmonary rehabilitation (PR), including exercise training and education, is therefore recommended for these patients. ${ }^{5,6}$ The aim of PR is not only to improve exercise capacity, dyspnea and quality of life ${ }^{7}$ but also to promote behavior changes in order to maintain long-term adherence to health-enhancing comportments, including exercise maintenance. ${ }^{5}$ The behavior changes necessary to maintain an in-home exercise program are driven by the cognitive functions which refer to a high-order neural process that underpins information handling by which a behavior can be adapted. ${ }^{8,9}$ However, cognitive dysfunction is another 
systemic feature impairment associated with COPD and may be as prevalent as $88 \%$ in hypoxic subjects. ${ }^{9}$ Although the mechanisms have not been clearly elucidated yet, these may involve chronic hypoxemia, chronic hypercapnia, lung function impairment, systemic inflammation, inactivity, smoking, cerebral atrophy or structural changes and repeated acute exacerbations. $^{8-10}$

Cognitive dysfunction in COPD is associated with worst outcome such as altered quality of life, ${ }^{11}$ higher rate of hospitalization $^{12}$ or death, ${ }^{8,9,12,13}$ as well as with unsuitable health behavior, such as poor intake of inhaled treatments ${ }^{14}$ or difficulties in smoking cessation. ${ }^{15}$ However, little is known about its prevalence among those subjects referred for $\mathrm{PR}^{16,17}$ and how it may affect the benefit or PR. ${ }^{18}$ Though some studies have shown a potential improvement in cognitive function with $\mathrm{PR},{ }^{19,20}$ little is known about whether these benefits are subsequently maintained and whether they impact exercise maintenance following $\mathrm{PR} .{ }^{21}$ In addition, because of a limited access to PR (mainly located in urban areas) and a number of barriers to attend or participate in, ${ }^{22-}$ ${ }^{24} \mathrm{PR}$ is often delivered in the home environment with the use of telehealth technologies. ${ }^{25}$ However, the impact of cognitive function on the usability of telehealth technology usually used to deliver in-home PR has not been studied yet. Therefore, we hypothesized that cognitive dysfunction is highly prevalent among those people with COPD referred for PR but has the potential to improve following PR. Additionally, we hypothesized that cognitive dysfunction may impede with the positive effect of PR as well as with the usability of telehealth technology and exercise maintenance following PR.

The primary aims of this study were to assess the prevalence of cognitive dysfunction among people with COPD referred for PR and the mid-term effects of PR on cognitive function (3 months after completion). Secondary objectives were to assess how cognitive dysfunction may affect the benefit of PR, telehealth technology usability and exercise maintenance following PR.

\section{Methods}

\section{Study Design and Participants}

This prospective multicenter observational study was approved by the French Ethics Committee Ile de France 1 (2017-juin-14586 ND), was prospectively registered at https://www.clinicaltrials.gov (NCT03244137) and conducted in accordance with the Declaration of Helsinki.
Subjects with a clinical diagnosis of COPD referred for PR at ADIR Association, Rouen University Hospital, France and Jacques Monod Hospital, Le Havre, France, were screened for eligibility between August 2017 and June 2019. They had to be 18 years and over, have a forced expiratory volume in $1 \mathrm{~s}$ (FEV1) $<50 \%$ and be eligible to PR (ie, exertional or rest dyspnea and no medical contraindication to exercise). Subjects were not included if they were hospitalized for an acute exacerbation within the previous 3 months, ${ }^{11,26}$ had an active alcoholism or had a history of psychiatric or neurovascular disease, cranial trauma, or other known disease associated with cognitive dysfunction. Other non-inclusion criteria included pregnancy or likely to be and guardianship. Subjects were excluded if the PR program was interrupted for more than 14 days due to severe acute exacerbation of COPD, ${ }^{11,26}$ if they disrupted training before 18 sessions or performed less than 18 sessions in 4 months (non-adherent subjects). Written informed consent was obtained from all patients.

\section{Clinical and Functional Assessment}

Before attending the PR program and prior to participating in the study, every subject underwent an evaluation including pulmonary function tests ${ }^{27}$ and cardiopulmonary exercise testing (CPET). ${ }^{28}$

\section{Pulmonary Rehabilitation Program}

Every subject participated in a 3 times per week for 8 weeks comprehensive outpatient PR program including respiratory physiotherapy, muscle strengthening, endurance training, self-management and nutritional support as necessary.

Peripheral muscle strengthening ( 3 sets of 12 movements at $70 \%$ of the one repetition maximum or using resistive bands) mainly focused on the lower limbs. Endurance training was progressive (from 15 to $45 \mathrm{mins}$, including a $5 \mathrm{mins}$ warm-up and a 5 mins cool down periods) and the intensity was adjusted at the anaerobic threshold (manually derived from the initial CPET as the average of 4 methods: first break the minute ventilation curve, rise in the minute ventilation to oxygen consumption ratio without modification of the minute ventilation to carbon dioxide production ratio, rise in the end-tidal expired carbon dioxide gas and the Beaver's method $\left.{ }^{28,29}\right)$. Subsequently, the intensity was increased based on perceived exertion (dyspnea or muscular fatigue assessed using the Borg scale ${ }^{30}$ as previously described $\left.{ }^{31}\right)$. 
The self-management program was also individualized and constructed according to the "Living Well with COPD » program, ${ }^{32}$ as well as with the French « Haute Autorité de Santé " guidelines for COPD selfmanagement. ${ }^{33}$ It covered the following topics: COPD knowledge, smoking cessation, management of acute exacerbations, inhaled treatments, physical activities, breathing management, healthy lifestyle, oxygen therapy, noninvasive ventilation, hobbies and traveling.

\section{Usability of a Telemonitoring System}

The first subjects were also invited to participate in a second prospective observational study aiming to assess whether subjects referred to pulmonary rehabilitation could easily learn to use a system for remote transmission of oximetry data. This second study, offered to every subject with chronic lung disease referred to pulmonary rehabilitation (without any other restriction) took place within the same period in both centres but ended earlier. ${ }^{34}$

Briefly, an investigator physiotherapist taught the participants how to use the telemonitoring system and subsequent sessions were scheduled to determine when the subjects became autonomous with transmitting their data via the telemonitoring system. ${ }^{34}$

\section{Outcomes}

Outcomes were assessed before PR, at the end of PR and 3 months following the completion of PR.

The primary outcome was cognitive function assessed with the Montreal Cognitive Assessment tool (MoCA). ${ }^{17,35,36}$ Three versions of the tool are currently available to avoid any learning effects and were used in a cross-over randomized order throughout the evaluations (computer-generated sequence and concealed allocation). The same investigator performed the three evaluations for a given patient. A screening cutoff $<26$ was used to assess the occurrence of mild cognitive dysfunction. ${ }^{17,36}$

Secondary outcomes were health-related quality of life using the Saint George's Respiratory Questionnaire total score and sub-scores, ${ }^{37}$ anxiety and depression using the Hospital Anxiety and Depression scale ${ }^{38}$ and functional capacity (only assessed before and at the end of PR) using the six-minute walk test $\mathrm{t}^{39}$ and the six-minute stepper test. ${ }^{40-42}$ In addition, autonomy in using the telemonitoring system was granted if the procedure was repeated successfully at the first session after initiation.

\section{Statistical Analysis}

The normality of the data was assessed using the Kolmogorov-Smirnov test. Categorical data were expressed as counts (\% and 95\% confidence interval (CI)) and continuous data were expressed as mean (SD) or median (25th-75th percentile) according to the distribution. Comparison of outcomes between baseline, following PR and 3 months following PR was performed using either repeated ANOVA (and Tukey post hoc tests) or a Friedman test (and a Wilcoxon test as a post hoc test for pairwise comparisons) according to the distribution. The change in the proportion of subjects with a MOCA score $<26$ was assessed using the Cochran test.

To assess the effects of cognitive dysfunction on the benefit of PR, exercise maintenance following PR and telehealth technology usability, subjects were separated into two groups according to their baseline score on the MOCA tool $(<26$ or $\geq 26)$. Difference in outcomes between groups was assessed using either an independent Student's $t$-test or a Mann-Whitney test for quantitative data and a Fisher exact test for categorical data. A p-value $<0.05$ was considered as statistically significant. SPPS software version 25 was used for all analyses.

\section{Results \\ Subjects}

Two hundred nine subjects were screened for eligibility and 56 were included in the study (Figure 1). Fifty-four percent of the participants were women, their mean age was 62 (SD 9) years, their median FEV1 was $0.9 \mathrm{~L}$ (IQR 0.7 to 1.1) and their aerobic capacity was decreased (mean VO2: 12 (SD 3) $\mathrm{mL} / \mathrm{kg} / \mathrm{min}$ ). Among them, 19 also participated in the assessment of the usability of a telemonitoring system. Mild cognitive dysfunction was found in 41 subjects ( $73 \%$ [ $95 \%$ CI: $60 \%$ to $83 \%$ ]). Their baseline characteristics were not significantly different from those people without cognitive dysfunction but they had the worst quality of life and a lower educational level (Table 1). Thirty-seven subjects were assessed following PR and 22 subjects 3 months thereafter (see Figure 1 for reasons of drop-out). Comparisons between subjects who did complete PR and those who did not, and between subjects that attended the 3 months follow-up and those who did not are shown in Table S1 and Table S2, respectively. The same comparisons for those subjects with a baseline MoCA $<26$ are shown in Table S3 and Table S4, respectively. 


\section{ONSORT \\ TRANSPARENT REPORTING Of TRIALS \\ CONSORT 2010 Flow Diagram}

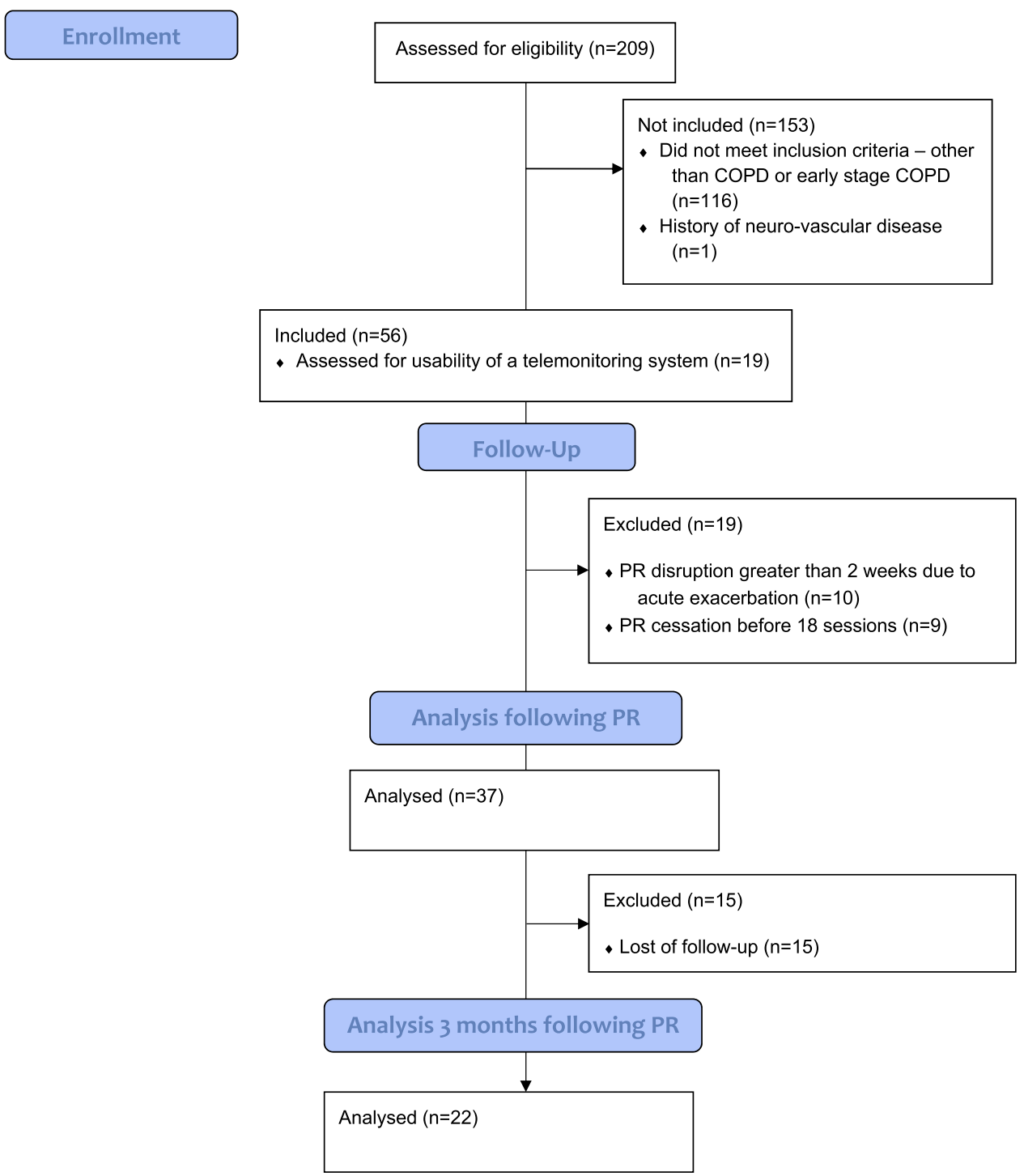

Figure I Study flow diagram.

\section{Primary Outcome}

The MoCA score significantly increased during the follow-up period $(\mathrm{p}<0.01)$, mainly due to a significant increase in the median score between baseline and 3 months following PR (from 22 (IQR 20 to 26) to 25 (IQR 23 to 28) respectively, $\mathrm{p}<0.01$ ). The median MoCA score remained unchanged among those people without baseline mild cognitive dysfunction $(\mathrm{p}=0.37)$ while it significantly increased among those people with baseline mild cognitive dysfunction $(\mathrm{p}<0.01)$ mainly due to a significant improvement at the end of PR (from 21 (IQR 20 to 24) to 22 (IQR 20 to 26 ), $\mathrm{p}<0.01$ ) which was sustained 3 months thereafter (median score: 24 (IQR 21 to 26), $\mathrm{p}<0.01$ ) (Figure 2A).

Among the cognitive domains, only the median memory score significantly increased from baseline to post PR (from 3 (IQR 2 to 4 ) to 3 (IQR 3 to 5 ), p=0.04) and 3 months thereafter ( 4 (IQR 3 to 5 ), $\mathrm{p}<0.01$ ). It was 
Table I Demographic Characteristics of the Patients

\begin{tabular}{|c|c|c|c|c|}
\hline \multirow[t]{2}{*}{ Characteristics } & \multicolumn{3}{|l|}{ Patients } & \multirow{2}{*}{$\begin{array}{l}\text { Between-Group } \\
\text { Comparison } \\
p\end{array}$} \\
\hline & $\begin{array}{l}\text { Total } \\
(n=56)\end{array}$ & $\begin{array}{l}\text { MoCA }<26 \\
(n=4 I)\end{array}$ & $\begin{array}{l}\text { MoCA } \geq 26 \\
(n=15)\end{array}$ & \\
\hline Gender, $\mathrm{n}$ female (\%) & $30(54)$ & $20(49)$ & $10(67)$ & 0.37 \\
\hline Age $(y r)$, mean $(S D)$ & $62(9)$ & $64(9)$ & $59(11)$ & 0.13 \\
\hline Body mass index $\left(\mathrm{kg} / \mathrm{m}^{2}\right)$, mean $(\mathrm{SD})$ & $24.5(5.2)$ & $25(5.5)$ & $23.3(4.2)$ & 0.29 \\
\hline $\mathrm{FEV}_{\text {, }}(\mathrm{L})$, median (IQR) & 0.9 (0.7 to I.I) & 0.9 (0.6 to I.2) & $\mathrm{I} .0(0.7$ to $\mathrm{I} . \mathrm{I})$ & 0.62 \\
\hline FEV (\%), median (IQR) & 36 (28 to 44$)$ & 36 (28 to 44$)$ & 39 (32 to 44$)$ & 0.56 \\
\hline FVC (L), median (IQR) & 2.3 (I.7 to 2.7$)$ & 2.2 (I.6 to 2.7$)$ & $2.3(2.1$ to 3.6$)$ & 0.36 \\
\hline FEV/FVC (\%), mean (SD) & $4 I(10)$ & $4 I(10)$ & $40(9)$ & 0.85 \\
\hline Residual volume (L), mean (SD) & $4.1(1.3)$ & $4.2(1.3)$ & $3.8(1.2)$ & 0.35 \\
\hline TLC (L), mean (SD) & $6.6(1.4)$ & $6.7(1.4)$ & $6.4(1.5)$ & 0.52 \\
\hline $\mathrm{VO}_{2 \text { peak }}(\mathrm{mL} / \mathrm{kg} / \mathrm{min})$, mean $(\mathrm{SD})$ & $12(3)$ & $12(3)$ & $14(3)$ & 0.06 \\
\hline $\mathrm{W}_{\text {peak }}(\mathrm{W})$, median (IQR) & 50 (39 to 63$)$ & 45 (36 to 60$)$ & 55 (39 to 73$)$ & 0.17 \\
\hline 6MST (steps), median (IQR) & 179 (1 I3 to 209$)$ & 148 (103 to 202$)$ & 191 (156 to 246$)$ & 0.08 \\
\hline 6MWT (meters), mean (SD) & $386(115)$ & $377(117)$ & $409(112)$ & 0.39 \\
\hline BODE index, mean (SD) & $5(2)$ & $5(2)$ & $4(1)$ & 0.09 \\
\hline Long-term oxygen, n (\%) & $27(48)$ & $22(54)$ & $5(33)$ & 0.23 \\
\hline Home non-invasive ventilation, $\mathrm{n}(\%)$ & $7(13)$ & $6(15)$ & I (7) & 0.66 \\
\hline HAD-Anxiety, mean (SD) & $10(4)$ & $10(4)$ & $9(5)$ & 0.42 \\
\hline HAD-Depression, median (SD) & $8(5$ to 10$)$ & $8(6$ to 9$)$ & $6(4$ to 11$)$ & 0.50 \\
\hline $\begin{array}{l}\text { Saint Georges Respiratory Questionnaire (\%), } \\
\text { mean (SD) }\end{array}$ & $58(16)$ & $62(15)$ & $46(15)$ & $<0.01$ \\
\hline MoCA, median (IQR) & $22(20$ to 26$)$ & 21 (20 to 24$)$ & 27 (26 to 28$)$ & $<0.01$ \\
\hline Educational level $^{\mathrm{a}}$ & & & & 0.01 \\
\hline Level I, n (\%) & I (2) & I (2) & $0(0)$ & \\
\hline Level II, n (\%) & $5(9)$ & I (2) & $4(27)$ & \\
\hline Level III, n (\%) & $2(4)$ & I (2) & I (7) & \\
\hline Level IV, n (\%) & $8(14)$ & $4(10)$ & $4(27)$ & \\
\hline Level V, n (\%) & $17(30)$ & $14(34)$ & $3(20)$ & \\
\hline Level VI, n (\%) & $23(4 I)$ & $20(49)$ & $3(20)$ & \\
\hline \multicolumn{5}{|l|}{ Comorbidities } \\
\hline Hypertension, n (\%) & $20(36)$ & $15(37)$ & $5(33)$ & 1.00 \\
\hline Hypercholesterolemia, n (\%) & $10(18)$ & $9(22)$ & I (7) & 0.26 \\
\hline Diabetes, n (\%) & $4(7)$ & $\mathrm{I}(2)$ & $3(20)$ & 0.06 \\
\hline Cardiopathies, n (\%) & $10(18)$ & $8(20)$ & $2(13)$ & 0.71 \\
\hline Surgery for NSCLC, n (\%) & $7(13)$ & $5(12)$ & $2(13)$ & 1.00 \\
\hline History of other cancer, $n(\%)$ & $7(13)$ & $5(12)$ & $2(13)$ & 1.00 \\
\hline
\end{tabular}

Notes: Fisher test for categorical data. Mann-Whitney or independent t-test for other characteristics. Percentages may not sum to 100 due to rounding. ${ }^{2}$ Educational level was assessed according to the French National Institute of Statistics and Economic Studies Classification. Educational level ranged from I (Msc and higher) to V (interruption of the schooling during the first cycle of secondary education (before 16 years)).

Abbreviations: $\mathrm{FEV}_{1}$, forced expiratory volume in I s; FVC, forced vital capacity; TLC, total lung capacity; $\mathrm{VO}_{2 \text { peak, }}$ maximal oxygen consumption; $\mathrm{W}_{\text {peak }}$, maximal workload achieved during cardiopulmonary exercise testing; 6MST, six-minute stepper test; 6MWT, six-minute walk test; BODE, body-mass index; obstructive; dyspnea and exercise capacity index; HAD, anxiety and depression scale; MoCA, Montreal Cognitive Assessment tool; NSCLC, non-small-cell lung cancer.

further improved from post PR to 3 months following PR ( $p=0.04$ ) (Figure 2B). There was no significant change in the proportion of people with mild cognitive dysfunction during the follow-up ( $\mathrm{p}=0.20)$.

\section{Secondary Outcomes}

In the total population, PR significantly improved exercise capacity (6MST and 6MWT) and the SGRQ impact subscore. The SGRQ impact sub-score was further improved 


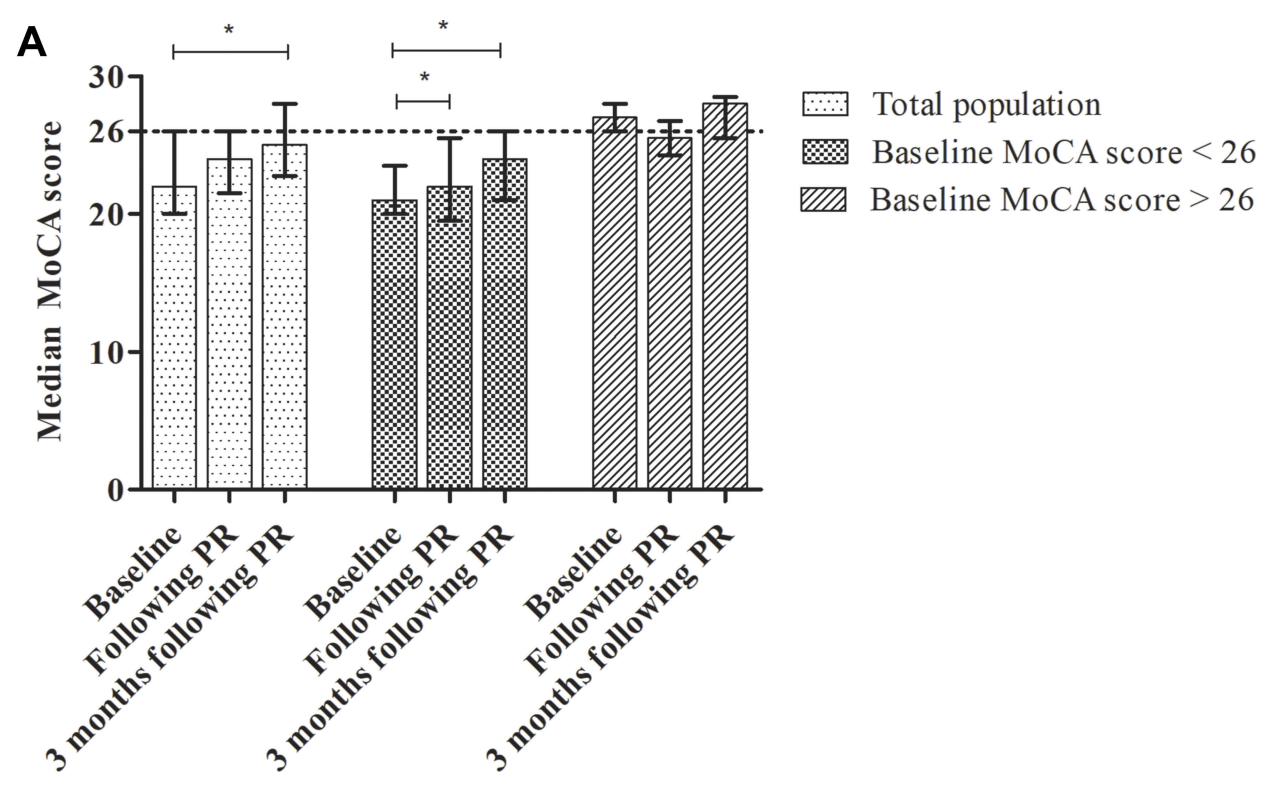

B
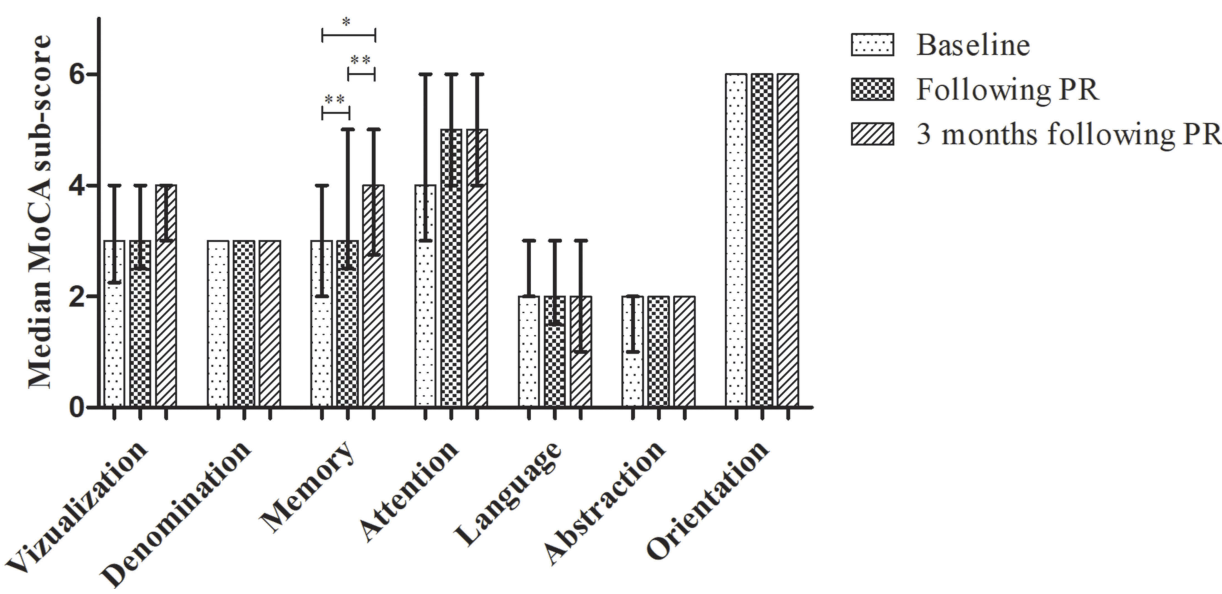

Figure 2 Evolution of the Montreal Cognitive Assessment tool total score (A) and sub-score (B). Data are shown as median (25th-75th percentile). Friedman test and Wilcoxon as a post hoc test for pairwise comparison for within-group comparison. Baseline: $n=56$; following PR: $n=37,3$ months following PR: $n=22$. * $P<0.01 * * p=0.04$.

3 months thereafter $(\mathrm{p}=0.02)$ (Table 2). There was no significant difference in outcomes between those people with or without mild cognitive dysfunction either following PR or at 3 months except for the median 6MST which was significantly higher for those people without mild cognitive dysfunction (218 (IQR 162 to 263) steps compared with 182 (IQR 121 to 310 ) steps, $\mathrm{p}=0.03$ ) (Table 2).

The proportion of subjects who maintained a physical activity was not significantly different between those with or without mild cognitive dysfunction following PR (57\% compared with $63 \%$, respectively, $\mathrm{p}=1$ ). The MoCA score 3 months following PR was not significantly different between those people who maintained a physical activity or not (24 (SD 3) and 25 (SD 3) respectively, p=0.71)
Finally, 10 out of 12 subjects ( $83 \%$ ) with mild cognitive dysfunction were autonomous in using the telemonitoring system which was not significantly different from those subjects without mild cognitive dysfunction (5 out of $7(71 \%), p=0.60)$.

\section{Relationship Between the MoCA Score and Outcomes}

At baseline, the MoCA score was negatively correlated with the SGRQ total score $(r=-0.28, p=0.04$; ie a higher score on the MoCA tool was associated with a better quality of life). The change in the MoCA score was not significantly associated with a change in any outcome following PR. 
Table 2 Change in Secondary Outcomes Following and 3 Months After PR

\begin{tabular}{|c|c|c|c|c|}
\hline \multirow[t]{2}{*}{ Outcome } & \multicolumn{3}{|l|}{ Timepoint } & \multirow{2}{*}{ Within Group } \\
\hline & $\begin{array}{l}\text { Baseline } \\
(n=56)\end{array}$ & $\begin{array}{l}\text { Following PR } \\
(n=37)\end{array}$ & $\begin{array}{l}3 \text { Months After PR } \\
(n=22)\end{array}$ & \\
\hline 6MST (steps), median (IQR) & $179(113-209)$ & $183(160$ to 273$)$ & & $<0.01$ \\
\hline Baseline MoCA $<26$ & I 48 (103 to 202$)$ & $182(12 \mid$ to $3 \mid 0)$ & & $<0.01$ \\
\hline Baseline MoCA $\geq 26$ & 191 (156 to 246$)$ & $218(162$ to 263$)$ & & 0.03 \\
\hline Between group $p$ & 0.08 & 0.03 & & \\
\hline 6MWT (meters), mean (SD) & $386(115)$ & $418(108)$ & & 0.01 \\
\hline Baseline MoCA $<26$ & $377(117)$ & $405(116)$ & & 0.10 \\
\hline Baseline MoCA $\geq 26$ & $409(112)$ & $443(88)$ & & 0.08 \\
\hline Between group $p$ & 0.39 & 0.37 & & \\
\hline HAD-Anxiety, mean (SD) & $10(4)$ & $8(4)$ & $8(4)$ & 0.59 \\
\hline Baseline MoCA $<26$ & $10(4)$ & $9(4)$ & $9(4)$ & 0.67 \\
\hline Baseline MoCA $\geq 26$ & $9(5)$ & $7(3)$ & $6(3)$ & 0.68 \\
\hline Between group $p$ & 0.42 & 0.12 & 0.14 & \\
\hline HAD-Depression, mean (SD) & $8(3)$ & $7(4)$ & $6(3)$ & 0.17 \\
\hline Baseline MoCA $<26$ & $8(3)$ & $7(4)$ & $7(4)$ & 0.45 \\
\hline Baseline MoCA $\geq 26$ & $7(4)$ & $6(4)$ & $6(3)$ & 0.78 \\
\hline Between group $\mathrm{P}$ & 0.53 & 0.62 & 0.79 & \\
\hline SGRQ (\%) - total score, mean (SD) & $58(16)$ & $51(14)$ & $51(14)$ & 0.11 \\
\hline Baseline MoCA $<26$ & $62(15)$ & $53(13)$ & $54(14)$ & 0.11 \\
\hline Baseline MoCA $\geq 26$ & $46(15)$ & $47(15)$ & $4 I(12)$ & 0.47 \\
\hline Between group $p$ & $<0.01$ & 0.19 & 0.09 & \\
\hline SGRQ (\%) - symptom sub-score, mean (SD) & $54(22)$ & $50(20)$ & $47(20)$ & 0.57 \\
\hline Baseline MoCA $<26$ & $56(21)$ & $46(2 I)$ & $48(21)$ & 0.73 \\
\hline Baseline MoCA $\geq 26$ & $50(24)$ & $57(17)$ & $43(18)$ & 0.95 \\
\hline Between group $p$ & 0.35 & 0.14 & 0.66 & \\
\hline SGRQ (\%) - activity sub-score, median (IQR) & 77 (60 to 91$)$ & 73 (56 to 86$)$ & 73 (60 to 86$)$ & 0.85 \\
\hline Baseline MoCA $<26$ & 80 (65 to 93$)$ & 73 (60 to 86$)$ & $74(61$ to 86$)$ & 0.51 \\
\hline Baseline MoCA $\geq 26$ & 65 (52 to 81$)$ & $66(54$ to 80$)$ & $60(57$ to 76$)$ & 0.54 \\
\hline Between group $p$ & 0.02 & 0.17 & 0.09 & \\
\hline SGRQ (\%) - impact sub-score, median (IQR) & 46 (39 to 62$)$ & $43(24 \text { to } 55)^{*}$ & $39(32 \text { to } 46)^{*} \neq$ & 0.02 \\
\hline Baseline MoCA $<26$ & 51 (42 to 66$)$ & 45 (33 to 56$)$ & $43(33 \text { to } 47)^{*}$ & 0.03 \\
\hline Baseline MoCA $\geq 26$ & 39 (20 to 46$)$ & 33 (15 to 54$)$ & 37 (11 to 39$)$ & 0.73 \\
\hline Between groups $p$ & $<0.01$ & 0.13 & 0.09 & \\
\hline
\end{tabular}

Notes: Repeated ANOVA and Tukey post hoc tests or Friedman test and Wilcoxon as a post hoc test for pairwise comparison for within-group comparison. MannWhitney or independent $t$-test for between-group comparison. *Significantly different from baseline, $p<0.05$. $\neq$ Significantly different from following PR, $p<0.05$

Abbreviations: PR, pulmonary rehabilitation; 6MST, six-minute stepper test; 6MWT, six-minute walk test; HAD, anxiety and depression scale; SGRQ, Saint Georges Respiratory Questionnaire.

\section{Discussion}

The present study revealed that mild cognitive dysfunction was highly prevalent among people with severe to very severe COPD referred for PR (about 75\%) but may not affect the benefits of PR since there was no statistical or clinically relevant difference in outcomes between those people with or without mild cognitive dysfunction. In addition, PR had the potential to improve short and midterm cognitive function, particularly for those people who experienced mild cognitive dysfunction at the time they were referred to PR. Finally, mild cognitive dysfunction was not associated with a worst rate of exercise maintenance following PR nor with a worst rate of usability of a telemonitoring system. 


\section{Cognitive Function and Pulmonary Rehabilitation}

The prevalence of mild cognitive dysfunction was relatively high in the present cohort (73\%) compared with previous studies which also used the MoCA score as a screening tool (from $10 \%$ to $18 \%$ ). ${ }^{16,17}$ This difference may be explained by the severity of the subjects recruited since the worsening of the respiratory function and/or chronic hypoxia ( $48 \%$ of long-term users) have been associated with cognitive dysfunction. ${ }^{43-46}$ The present results extend those from previous studies showing a positive effect of PR on cognitive function ${ }^{19,20,47}$ particularly for those people who experienced mild cognitive dysfunction when attending PR. The physiological explanation underlying this improvement remains unclear but may include repetitive acute bouts of exercise sessions which contribute to increasing cardiac output and neurotransmitters release during exercise, ${ }^{48}$ benefit of social exchanges during group exercise sessions as well as PR-induced neural changes. ${ }^{49}$

An additional important finding was that this positive effect was subsequently maintained 3 months following PR. Contrary to Emery et al, who found that the improvement in cognitive function was maintained at 1 year following PR only for those people who continued with a regular program of moderate-intensity exercise, ${ }^{21}$ we did not find such an association, suggesting a residual effect of the initial program on cognitive function up to 3 months. This is of interest since this period is a hinge between the supervised program and the less or unsupervised long-term maintenance program which requires a cognitive function-directed behavior change. Though the preliminary results of this study suggest that cognitive dysfunction may not negatively affect exercise maintenance following PR, this should further be studied.

On the other hand, in the absence of a known minimal clinical important difference (MCID) for the MoCA score and considering than both the median score remained below 26 and the proportion of subjects with mild cognitive impairment did not significantly change during the follow-up period, the clinical relevance of the present findings remains questionable. Therefore, further study should consider to assess the MCID for the MoCA score, which offers the advantage to be easier to perform in clinical practice than more comprehensive cognitive function battery tests.

\section{Impact of Cognitive Functions on PR Outcomes}

Following PR, both those people with or without mild cognitive dysfunction significantly and clinically improved their performance on the 6MST $\left(>20\right.$ steps $\left.^{50}\right)$. The between-group difference following PR probably reflects the trend observed at baseline towards a lower performance for those people with mild cognitive dysfunction $(p=0.08)$ so that the actual difference in improvement between groups is likely clinically trivial. In addition, the mean improvement in the 6MWT also lied within the range of the established MCID ( 25 to $33 \mathrm{~m}^{39}$ ) for the total population $(\mathrm{p}=0.01)$ and both subgroups. However, the latter failed to reach statistical significance due to a loss in statistical power. Contrary to Emery et al, we did not find any improvement in psychological wellbeing ${ }^{19,20}$ but found a clinical improvement $(>4$ points $^{37}$ ) in the SGRQ impact sub-score following and 3 months after PR, particularly in those people having a baseline mild cognitive dysfunction. In addition, neither the baseline MoCA score nor the change in the MoCA score was significantly associated with outcomes changes following PR. Altogether, these results extend those from a previous study ${ }^{18}$ and suggest that cognitive dysfunction may not alter the progression during PR when subjects are closely supervised.

\section{Implication for Practice and Research}

Though cognitive dysfunction may not impede the effectiveness of supervised PR, the access to such programs is limited. $^{22-24}$ To cope with this difficulty, PR may be delivered in the home environment but this often implies a lower level of supervision. ${ }^{51,52}$ Alternatively, home-based PR may provide supervision that center-based pulmonary rehabilitation provides if it uses new technologies to allow remote telemonitoring and therapists' prompt feedback. Reassuringly, this study provides preliminary evidence than people with mild cognitive dysfunction are able to use user-friendly telemonitoring system $(83 \%$ were autonomous at the first session after initiation which was not significantly different from those people without mild cognitive dysfunction $(71 \%, p=0.60)$ and within the range of the success rate of the overall cohort $\left.(86 \%)^{34}\right)$. Since memory was significantly improved following PR in the present study, this strengthens the idea that subjects should be able to keep using this system throughout the program. Therefore, future studies should now assess the feasibility, safety and 
effectiveness of a telemonitoring home-based PR for those people with COPD-related mild cognitive dysfunction.

\section{Limits of the Study}

The main limitations of this study were the lack of a control group without PR and the small sample size studied. In addition, the dropout rate was relatively high but comparable to the rate in other studies about PR. ${ }^{52-54}$ However, those people who did not complete PR or did not attend the 3-month follow-up did not significantly differ from those who completed the overall study, suggesting a lack of selection bias. Nonetheless, this high attrition contributed to decreasing the power of the study which may have led to some type 2 statistical errors. Therefore, the lack of difference between those subjects with or without mild cognitive dysfunction on PR outcomes or telehealth system usability should be considered as exploratory.

\section{Conclusion}

Mild cognitive dysfunction is highly prevalent among those people with severe to very severe COPD referred for PR (about three quarter) but may not affect the benefits of PR. PR may improve short and mid-term cognitive function, particularly for those people who experience mild cognitive dysfunction at the time they are referred to PR. Finally, mild cognitive dysfunction may not affect exercise maintenance following PR nor the usability of a user-friendly telemonitoring system.

\section{Registration}

The protocol was prospectively registered on www.clinical trials.gov (NCT03244137).

\section{Abbreviations}

CI, confidence intervals; COPD, chronic obstructive pulmonary disease; CPET, cardiopulmonary exercise testing; FEV1, forced expiratory volume in $1 \mathrm{~s}$; MCID, minimal clinical important difference; MoCA, Montreal Cognitive Assessment tool; PR, pulmonary rehabilitation.

\section{Data Sharing Statement}

De-identified participant data published in the manuscript will be shared to searcher performing a meta-analysis on request. Data will be available after publication. Please, contact Tristan Bonnevie (rehabilitation@adir-hautenormandie. com) for query.

\section{Ethics and Consent Statement}

This prospective observational study was approved by the French Ethics Committee Ile de France 1 (2017-juin-14586 ND). Written consent was obtained from all subjects.

\section{Acknowledgments}

This work was supported by the ADIR Association. We thank Emeline Fresnel and Adrien Kerfourn (KerNel Biomedical, Rouen, France) for statistical support.

\section{Author Contributions}

All authors contributed to data analysis, drafting or revising the article, gave final approval of the version to be published, and agree to be accountable for all aspects of the work.

\section{Disclosure}

TB reports a grant from Fisher \& Paykel outside the submitted work. The authors report no funding and no other possible conflicts of interest for this work.

\section{References}

1. Lozano R, Naghavi M, Foreman K, et al. Global and regional mortality from 235 causes of death for 20 age groups in 1990 and 2010: a systematic analysis for the Global Burden of Disease Study 2010. Lancet. 2012;380(9859):2095-2128. doi:10.1016/S0140-6736(12) 61728-0

2. Halbert RJ, Natoli JL, Gano A, Badamgarav E, Buist AS, Mannino DM. Global burden of COPD: systematic review and meta-analysis. Eur Respir J. 2006;28(3):523-532. doi:10.1183/09031936.06.00124605

3. Khakban A, Sin DD, FitzGerald JM, et al. The projected epidemic of chronic obstructive pulmonary disease hospitalizations over the next 15 years. a population-based perspective. Am J Respir Crit Care Med. 2017;195(3):287-291. doi:10.1164/rccm.201606-1162PP

4. Ramon MA, Ter Riet G, Carsin AE, et al. The dyspnoea-inactivity vicious circle in COPD: development and external validation of a conceptual model. Eur Respir J. 2018;52(3):1800079. doi:10.1183/ 13993003.00079-2018

5. Spruit MA, Singh SJ, Garvey C, et al. An official American Thoracic Society/European Respiratory Society statement: key concepts and advances in pulmonary rehabilitation. Am J Respir Crit Care Med. 2013;188(8):e13-64. doi:10.1164/rccm.201309-1634ST

6. Vogiatzis I, Rochester CL, Spruit MA, Troosters T, Clini EM. American Thoracic Society/European Respiratory Society Task Force on Policy in Pulmonary R. Increasing implementation and delivery of pulmonary rehabilitation: key messages from the new ATS/ERS policy statement. Eur Respir J. 2016;47(5):1336-1341. doi:10.1183/13993 003.02151-2015

7. McCarthy B, Casey D, Devane D, Murphy K, Murphy E, Lacasse Y. Pulmonary rehabilitation for chronic obstructive pulmonary disease. Cochrane Database Syst Rev. 2015;2(2):CD003793.

8. Dodd JW, Getov SV, Jones PW. Cognitive function in COPD. Eur Respir J. 2010;35(4):913-922. doi:10.1183/09031936.00125 109

9. Cleutjens FA, Janssen DJ, Ponds RW, Dijkstra JB, Wouters EF. COgnitive-pulmonary disease. Biomed Res Int. 2014;2014:697825. doi:10.1155/2014/697825 
10. Yin M, Wang H, Hu X, Li X, Fei G, Yu Y. Patterns of brain structural alteration in COPD with different levels of pulmonary function impairment and its association with cognitive deficits. BMC Pulm Med. 2019;19(1):203. doi:10.1186/s12890-019-0955-y

11. Dodd JW, Charlton RA, van den Broek MD, Jones PW. Cognitive dysfunction in patients hospitalized with acute exacerbation of COPD. Chest. 2013;144(1):119-127. doi:10.1378/chest.12-2099

12. Chang SS, Chen S, McAvay GJ, Tinetti ME. Effect of coexisting chronic obstructive pulmonary disease and cognitive impairment on health outcomes in older adults. J Am Geriatr Soc. 2012;60(10):1839-1846. doi:10.1111/j.1532-5415.2012.04171.x

13. Antonelli-Incalzi R, Corsonello A, Pedone C, et al. Drawing impairment predicts mortality in severe COPD. Chest. 2006;130 (6):1687-1694. doi:10.1378/chest.130.6.1687

14. Allen SC, Jain M, Ragab S, Malik N. Acquisition and short-term retention of inhaler techniques require intact executive function in elderly subjects. Age Ageing. 2003;32(3):299-302. doi:10.1093/ageing/32.3.299

15. Brega AG, Grigsby J, Kooken R, Hamman RF, Baxter J. The impact of executive cognitive functioning on rates of smoking cessation in the San Luis valley health and aging study. Age Ageing. 2008;37 (5):521-525. doi:10.1093/ageing/afn121

16. Pierobon A, Ranzini L, Torlaschi V, et al. Screening for neuropsychological impairment in COPD patients undergoing rehabilitation. PLoS One. 2018;13(8):e0199736. doi:10.1371/journal.pone.0199736

17. Pierobon A, Sini Bottelli E, Ranzini L, et al. COPD patients' selfreported adherence, psychosocial factors and mild cognitive impairment in pulmonary rehabilitation. Int J Chron Obstruct Pulmon Dis. 2017;12:2059-2067. doi:10.2147/COPD.S133586

18. Cleutjens F, Spruit MA, Ponds R, et al. The impact of cognitive impairment on efficacy of pulmonary rehabilitation in patients with COPD. $\mathrm{J} \mathrm{Am}$ Med Dir Assoc. 2017;18(5):420-426. doi:10.1016/j.jamda.2016.11.016

19. Emery CF, Schein RL, Hauck ER, MacIntyre NR. Psychological and cognitive outcomes of a randomized trial of exercise among patients with chronic obstructive pulmonary disease. Health Psychol. 1998;17 (3):232-240. doi:10.1037/0278-6133.17.3.232

20. Emery CF, Leatherman NE, Burker EJ, MacIntyre NR. Psychological outcomes of a pulmonary rehabilitation program. Chest. 1991;100 (3):613-617. doi:10.1378/chest.100.3.613

21. Emery CF, Shermer RL, Hauck ER, Hsiao ET, MacIntyre NR. Cognitive and psychological outcomes of exercise in a 1-year follow-up study of patients with chronic obstructive pulmonary disease. Health Psychol. 2003;22(6):598-604. doi:10.1037/0278-6133.22.6.598

22. Cox NS, Oliveira CC, Lahham A, Holland AE. Pulmonary rehabilitation referral and participation are commonly influenced by environment, knowledge, and beliefs about consequences: a systematic review using the theoretical domains framework. $J$ Physiother. 2017;63(2):84-93. doi:10.1016/j.jphys.2017.02.002

23. Keating A, Lee A, Holland AE. What prevents people with chronic obstructive pulmonary disease from attending pulmonary rehabilitation? A systematic review. Chron Respir Dis. 2011;8(2):89-99. doi: $10.1177 / 1479972310393756$

24. Keating A, Lee AL, Holland AE. Lack of perceived benefit and inadequate transport influence uptake and completion of pulmonary rehabilitation in people with chronic obstructive pulmonary disease: a qualitative study. J Physiother. 2011;57(3):183-190. doi:10.1016/ S1836-9553(11)70040-6

25. Tsai LL, McNamara RJ, Moddel C, Alison JA, McKenzie DK, McKeough ZJ. Home-based telerehabilitation via real-time videoconferencing improves endurance exercise capacity in patients with COPD: the randomized controlled TeleR study. Respirology (Carlton, Vic). 2017;22(4):699-707. doi:10.1111/resp.12966

26. Ambrosino N, Bruletti G, Scala V, Porta R, Vitacca M. Cognitive and perceived health status in patient with chronic obstructive pulmonary disease surviving acute on chronic respiratory failure: a controlled study. Intensive Care Med. 2002;28(2):170-177. doi:10.1007/s00134001-1165-6
27. Quanjer PH, Tammeling GJ, Cotes JE, Pedersen OF, Peslin R, Yernault JC. Lung volumes and forced ventilatory flows. Report working party standardization of lung function tests, european community for steel and coal. Official statement of the european respiratory society. Eur Respir J Suppl. 1993;16:5-40. doi:10.1183/ $09041950.005 \mathrm{~s} 1693$

28. American Thoracic S. American College of Chest P. ATS/ACCP Statement on cardiopulmonary exercise testing. Am J Respir Crit Care Med. 2003;167(2):211-277.

29. Beaver WL, Wasserman K, Whipp BJ. A new method for detecting anaerobic threshold by gas exchange. J Appl Physio. 1986;60 (6):2020-2027. doi:10.1152/jappl.1986.60.6.2020

30. Borg GA. Psychophysical bases of perceived exertion. Med Sci Sports Exerc. 1982;14(5):377-381. doi:10.1249/00005768-198205000-00012

31. Maltais F, LeBlanc P, Jobin J, et al. Intensity of training and physiologic adaptation in patients with chronic obstructive pulmonary disease. Am J Respir Crit Care Med. 1997;155(2):555-561. doi:10.1164/ajrccm.155.2.9032194

32. Bourbeau J, Collet JP, Schwartzman K, Ducruet T, Nault D, Bradley C. Economic benefits of self-management education in COPD. Chest. 2006;130(6):1704-1711. doi:10.1378/chest.130.6.1704

33. HAS. Guide du parcours de soins - Bronchopneumopathie chronique obstructive. 2014:1-63

34. Bonnevie T, Gravier FE, Elkins M, et al. People undertaking pulmonary rehabilitation are willing and able to provide accurate data via a remote pulse oximetry system: a multicentre observational study. $J$ Physiother. 2019;65(1):28-36. doi:10.1016/j.jphys.2018.11.002

35. Karamanli H, Ilik F, Kayhan F, Pazarli AC. Assessment of cognitive impairment in long-term oxygen therapy-dependent COPD patients. Int J Chron Obstruct Pulmon Dis. 2015;10:2087-2094. doi:10.2147/ COPD.S88326

36. Villeneuve S, Pepin V, Rahayel S, et al. Mild cognitive impairment in moderate to severe COPD: a preliminary study. Chest. 2012;142 (6):1516-1523. doi:10.1378/chest.11-3035

37. Jones PW. Interpreting thresholds for a clinically significant change in health status in asthma and COPD. Eur Respir J. 2002;19 (3):398-404. doi:10.1183/09031936.02.00063702

38. Zigmond AS, Snaith RP. The hospital anxiety and depression scale. Acta Psychiatr Scand. 1983;67(6):361-370. doi:10.1111/j.16000447.1983.tb09716.x

39. Puente-Maestu L, Palange P, Casaburi R, et al. Use of exercise testing in the evaluation of interventional efficacy: an official ERS statement. Eur Respir J. 2016;47(2):429-460. doi:10.1183/13993003.007452015

40. Borel B, Fabre C, Saison S, Bart F, Grosbois JM. An original field evaluation test for chronic obstructive pulmonary disease population: the six-minute stepper test. Clin Rehabil. 2010;24(1):82-93. doi: $10.1177 / 0269215509343848$

41. Coquart JB, Lemaitre F, Castres I, Saison S, Bart F, Grosbois JM. Reproducibility and sensitivity of the 6-minute stepper test in patients with COPD. Copd. 2015;12(5):533-538. doi:10.3109/15412555. 2014.974733

42. Grosbois JM, Riquier C, Chehere B, et al. Six-minute stepper test: a valid clinical exercise tolerance test for COPD patients. Int J Chron Obstruct Pulmon Dis. 2016;11:657-663. doi:10.2147/ COPD.S98635

43. Schou L, Ostergaard B, Rasmussen LS, Rydahl-Hansen S, Phanareth K. Cognitive dysfunction in patients with chronic obstructive pulmonary disease-a systematic review. Respir Med. 2012;106 (8):1071-1081. doi:10.1016/j.rmed.2012.03.013

44. Cleutjens FA, Wouters EF, Dijkstra JB, et al. The COgnitive-Pulmonary Disease (COgnitive-PD) study: protocol of a longitudinal observational comparative study on neuropsychological functioning of patients with COPD. BMJ Open. 2014;4(3): e004495. doi:10.1136/bmjopen-2013-004495 
45. Dal Negro RW, Bonadiman L, Tognella S, Bricolo FP, Turco P. Extent and prevalence of cognitive dysfunction in chronic obstructive pulmonary disease, chronic non-obstructive bronchitis, and in asymptomatic smokers, compared to normal reference values. Int J Chron Obstruct Pulmon Dis. 2014;9:675-683. doi:10.2147/COPD.S63485

46. Roncero C, Campuzano AI, Quintano JA, Molina J, Perez J, Miravitlles M. Cognitive status among patients with chronic obstructive pulmonary disease. Int $J$ Chron Obstruct Pulmon Dis. 2016;11:543-551. doi:10.2147/COPD.S100850

47. Kozora E, Tran ZV, Make B. Neurobehavioral improvement after brief rehabilitation in patients with chronic obstructive pulmonary disease. J Cardiopulm Rehabil. 2002;22(6):426-430. doi:10.1097/ 00008483-200211000-00008

48. Emery CF, Honn VJ, Frid DJ, Lebowitz KR, Diaz PT. Acute effects of exercise on cognition in patients with chronic obstructive pulmonary disease. Am J Respir Crit Care Med. 2001;164(9):1624-1627. doi:10.1164/ajrccm.164.9.2104137

49. Herigstad M, Faull OK, Hayen A, et al. Treating breathlessness via the brain: changes in brain activity over a course of pulmonary rehabilitation. Eur Respir J. 2017;50:3. doi:10.1183/13993003. 01029-2017
50. Pichon R, Couturaud F, Mialon P, et al. Responsiveness and minimally important difference of the 6-minute stepper test in patients with chronic obstructive pulmonary disease. Respiration. 2016;91 (5):367-373. doi:10.1159/000446517

51. Holland AE, Mahal A, Hill CJ, et al. Home-based rehabilitation for COPD using minimal resources: a randomised, controlled equivalence trial. Thorax. 2017;72(1):57-65. doi:10.1136/thoraxjnl-2016208514

52. Horton EJ, Mitchell KE, Johnson-Warrington V, et al. Comparison of a structured home-based rehabilitation programme with conventional supervised pulmonary rehabilitation: a randomised non-inferiority trial. Thorax. 2018;73(1):29-36. doi:10.1136/thoraxjnl-2016-208506

53. Bonnevie T, Gravier FE, Debeaumont D, et al. Home-based neuromuscular electrical stimulation as an add-on to pulmonary rehabilitation does not provide further benefits in patients with chronic obstructive pulmonary disease: a multicenter randomized trial. Arch Phys Med Rehabil. 2018;99(8):1462-1470. doi:10.1016/j.apmr.20 18.01.024

54. Boutou AK, Tanner RJ, Lord VM, et al. An evaluation of factors associated with completion and benefit from pulmonary rehabilitation in COPD. BMJ Open Respir Res. 2014;1(1):e000051. doi:10.1136/ bmjresp-2014-000051

\section{Publish your work in this journal}

The International Journal of COPD is an international, peer-reviewed journal of therapeutics and pharmacology focusing on concise rapid reporting of clinical studies and reviews in COPD. Special focus is given to the pathophysiological processes underlying the disease, intervention programs, patient focused education, and self management protocols. This journal is indexed on PubMed Central, MedLine and CAS. The manuscript management system is completely online and includes a very quick and fair peer-review system, which is all easy to use. Visit http://www.dovepress.com/testimonials.php to read real quotes from published authors. 